\title{
QUALIDADE DO AR, AMBIENTE TÉRMICO E DESEMPENHO DE SUÍNOS CRIADOS EM CRECHES COM DIMENSÕES DIFERENTES ${ }^{1}$
}

\author{
JOSIANE A. CAMPOS ${ }^{2}$, ILDA DE F. F. TINÔCO ${ }^{3}$, FERNANDO DA C. BAÊTA ${ }^{4}$, \\ PAULO R. CECON ${ }^{5}$, ALDO L. MAURI ${ }^{6}$
}

\begin{abstract}
RESUMO: Em uma suinocultura, a fase de creche é considerada crítica, na qual o animal fica exposto às condições ambientais do recinto onde está alojado, sem a proteção da matriz e inserido em um meio social coletivo e desconhecido. Essa fase requer ambiente térmico mais aquecido e, por isso, em período de inverno, os abrigos são mantidos mais fechados, o que pode ser agravante em termos de renovação do ar. Este trabalho teve como objetivo avaliar duas creches de dimensões diferentes, em período de inverno, levando-se em consideração o ambiente térmico, a qualidade do ar e o desempenho dos animais alojados nessas instalações. Foram utilizadas duas creches com dimensões diferentes (I e II), ambas sem nenhum tipo de aquecimento. Foram feitas medições de concentrações instantâneas de $\mathrm{NH}_{3}(\mathrm{ppm}), \mathrm{CO}$ (ppm) e $\mathrm{CO}_{2}$ (ppm). Dados relativos ao conforto térmico ambiente (temperatura e umidade) foram coletados continuamente. Concluiu-se que a concentração dos gases $\mathrm{CO}_{2}$ e $\mathrm{NH}_{3}$, mensurados em ambas as creches, não atingiram níveis que possam causar danos à saúde dos animais; não houve concentração mensurável do gás monóxido de carbono em nenhuma das mesmas; o ambiente térmico nas creches, no período estudado, esteve em condições consideradas confortáveis.
\end{abstract}

PALAVRAS-CHAVE: ambiência animal, conforto térmico, instalação suinícola.

\section{AIR QUALITY, THERMAL ENVIRONMENT AND PERFORMANCE OF SWINES RAISED IN FARROWING WITH DIFFERENT DIMENSIONS}

\begin{abstract}
The phase of swine nursery is considered a critical one, in which the animal is exposed to environmental conditions of the premises on which it is located, without the matrix protection and inserted into a social collective and unknown environment. This phase requires a more heated thermal environment and, because of that, on winter time the shelters are kept more closed, which can cause damage in terms of renewing the air. This work has the objective of evaluating two different sizes of farrowing on winter time, considering thermal environment, air quality and performance of animals located in these facilities. We used two different sizes (I and II), both without any kind of heating. Were measured instantaneous concentrations of $\mathrm{NH}_{3}(\mathrm{ppm}), \mathrm{CO}$ (ppm) and $\mathrm{CO}_{2}$ (ppm). Data relating to thermal comfort environment (temperature and humidity) were collected continuously. It was concluded that the concentration of $\mathrm{CO}_{2}$ and $\mathrm{NH}_{3}$ gases, measured in both farrowing, did not reach levels that could harm the health of animals; with no measurable concentration of carbon monoxide gas in any of these, the thermal environment in the farrowing during the studied time was considered comfortable.
\end{abstract}

KEYWORDS: animal environment, thermal comfort, swine housing.

\footnotetext{
${ }^{1}$ Extraído da Dissertação de Mestrado do primeiro autor.

${ }^{2}$ Zootecnista, Doutora, Construções Rurais e Ambiência/DEA/UFV, Avenida Santa Rita 110/402, Viçosa - MG, Fone: (0XX31) 38925834, josianecampos77@yahoo.com.br

${ }^{3}$ Eng $^{\underline{a}}$ Agrícola, Prof ${ }^{\mathrm{a}}$ Adjunta, Departamento de Engenharia Agrícola, DEA/UFV, Viçosa-MG, iftinoco@ufv.br

${ }^{4}$ Eng ${ }^{\circ}$ Agrícola, Prof. Titular, Departamento de Engenharia Agrícola, DEA/UFV, Viçosa-MG, baeta@ufv.br

${ }^{5}$ Eng $^{\mathrm{O}}$ Agrônomo, Prof. Adjunto, Departamento de Informática, DPI/UFV, Viçosa-MG, cecon@ @pi.ufv.br

${ }^{6}$ Eng ${ }^{\circ}$ Agrônomo, Doutor, Departamento de Fitotecnia, DFT/UFV, Viçosa-MG, aldmauri@ yahoo.com.br

Recebido pelo Conselho Editorial em: 14-6-2007

Aprovado pelo Conselho Editorial em: 17-7-2007
} 


\section{INTRODUÇÃO}

$\mathrm{Na}$ fase de creche, os animais necessitam de ambiente mais aquecido. Como o Brasil é um país de clima quente, nem sempre há a necessidade de aquecedores artificiais em determinadas regiões e período do ano. Dependendo da dimensão da creche, o ambiente interno da instalação pode atender às necessidades dos leitões apenas com o manejo das cortinas e aberturas (mantendo o ambiente mais fechado). Contudo, entende-se que o tamanho da creche e do grupo social, bem como os números de animais alojados por prédio possam interferir no ambiente térmico, na qualidade do ar e no comportamento animal em termos de desempenho produtivo.

Segundo SCHMIDT et al. (2002), os gases mais presentes nas instalações para suínos são amônia, sulfeto de hidrogênio e dióxido de carbono. No inverno, quando a ventilação é reduzida para manter o calor, a concentração desses gases aumenta dentro das instalações.

De acordo com SAMPAIO et al. (2005), a amônia é um gás incolor, de odor acre (detectado pelo homem entre 5 - 20 ppm), tóxico e mais leve que o ar, resultante da decomposição microbiana (aeróbia e anaeróbia) de compostos nitrogenados excretados (fezes + urina) e emitida na sua forma volátil para o ar.

CARVALHO (2001) e NIOSH (2005) descrevem que são fatores de risco que favorecem a incidência de enfermidades respiratórias, por exemplo, a amônia no teor acima de 10 ppm, alta concentração de poeira, ventilação inadequada e volume de ar inferior a $3,0 \mathrm{~m}^{3}$ por animal.

LOTT (2003) comenta que o gás amônia na concentração de 25 ppm causa paralisação parcial das atividades dos cílios, deixando de eliminar agentes que podem causar enfermidades do sistema respiratório, como partículas de poeira, bactérias, fungos e vírus, e em níveis superiores a $50 \mathrm{ppm}$ pode ocorrer a total paralisação e até a destruição de alguns cílios, comprometendo ainda mais a saúde dos animais, implicando dificuldades respiratórias e criação de condições para a instalação de doenças respiratórias e influenciando no crescimento dos animais.

A importância de $\mathrm{NH}_{3}$ sobre o ganho de peso dos suínos é mostrada no experimento realizado por JENSEN (2002), o qual verificou que a redução do gás no ambiente dos animais, usando mistura de água e ácido sulfúrico no dejeto $(\mathrm{pH}$ diminuiu para 5,5), contribuiu para acréscimos de até $12 \%$ no ganho de peso dos animais $\left(959 \mathrm{~g} \mathrm{dia}^{-1}\right.$ para $\left.1.074 \mathrm{~g} \mathrm{dia}^{-1}\right) . \mathrm{O}$ experimento foi realizado com animais de peso médio de $25 \pm 5 \mathrm{~kg}$ e de $95 \mathrm{~kg}$.

A produção de $\mathrm{CO}_{2}$ por animais está diretamente relacionada com sua produção de calor, sendo essa função do seu peso corporal e do seu ambiente térmico. Estudos realizados com o dióxido de carbono $\left(\mathrm{CO}_{2}\right)$ e monóxido de carbono $(\mathrm{CO})$ evidenciam que, a partir de certos limites de concentração (3.000 ppm de $\mathrm{CO}_{2}$ e $10 \mathrm{ppm}$ de $\mathrm{CO}$ ), esses gases afetam a saúde dos suínos (NADER et al., 2002).

Com relação ao ambiente térmico, a temperatura ideal para suínos na fase de creche situa-se entre 24 e $20{ }^{\circ} \mathrm{C}$, devendo a temperatura do ar ser próxima dos $24{ }^{\circ} \mathrm{C}$ nas primeiras semanas de alojamento, e em torno de $20^{\circ} \mathrm{C}$ nas últimas. A temperatura do ar não deve ser acima de $31^{\circ} \mathrm{C}$ e abaixo de $8{ }^{\circ} \mathrm{C}$ nessa fase de criação (SILVA, 1999).

Pesquisa realizada por QUINIOUN et al. (2000), com suínos entre $25 \mathrm{~kg}$ e $110 \mathrm{~kg}$, constatou que o aumento ou a diminuição da ingestão de alimentos está relacionada com a oscilação da temperatura do ar. Quando essa variação foi de $\pm 1,5^{\circ} \mathrm{C}$, para as temperaturas do ar de 24 ou $28^{\circ} \mathrm{C}$, a ingestão extra de alimento nos períodos frios compensou a menor ingestão nos períodos quentes e não afetou o desempenho dos animais. Essa compensação não aconteceu quando a amplitude térmica foi de $\pm 3{ }^{\circ} \mathrm{C}$ ou $\pm 4,5^{\circ} \mathrm{C}$ para 24 ou $28^{\circ} \mathrm{C}$ de temperatura do ar, respectivamente; nesse caso, ocorreu menor ingestão alimentar e pior desempenho dos animais. 
A umidade relativa do ar assume importante papel como facilitador ou como complicador dos mecanismos de dissipação de calor por via evaporativa. Para suínos, a umidade ambiente ideal não deve ultrapassar 70\%, segundo SOUSA (2004), SAMPAIO et al. (2004), SARTOR et al. (2003), SILVA (1999) e TEIXEIRA (1997).

Um dos índices de conforto térmico mais utilizados é o índice de umidade e temperatura de globo negro (ITGU) desenvolvido por BUFFINGTON et al. (1981), que propuseram índice que considera, em um único valor, os efeitos da temperatura de bulbo seco, da umidade relativa, da radiação e da velocidade do ar. Esse índice tem sido usado para avaliar as condições de conforto animal (TOLON \& NÄÄS, 2005). Para atender às condições de conforto térmico dos leitões, as maternidades devem propiciar o ITGU em torno de 72 para as matrizes e 80 para os leitões (TURCO 1995).

As propriedades térmicas dos materiais são de grande importância para a explicação das oscilações da temperatura em um recinto. A resistência térmica de um material, por exemplo, expressa a resistência que o material oferece à passagem de calor, de acordo com TINÔCO et al. (2002); TINÔCO, (2001).

Outro fator inerente às construções é o número de animais por área. A densidade animal nos criatórios de suínos tem influência direta no desempenho dos animais. Para as instalações de suínos em confinamento, é necessário atender a alguns requisitos básicos estabelecidos pela área necessária por animal $\left(\mathrm{m}^{2}\right.$ por animal).

Segundo TEIXEIRA (1997), a área de instalação ( $\mathrm{m}^{2}$ por animal) necessária à criação de suínos na fase de creche deve ser de 0,20 a $0,38 \mathrm{~m}^{2}$ por animal, considerando-se um período de utilização de 4 a 5 semanas.

Diante desse contexto, este trabalho teve como objetivo avaliar a qualidade do ar (concentração de $\mathrm{CO}_{2}, \mathrm{CO}$ e $\mathrm{NH}_{3}$ ), o ambiente térmico e o desempenho de suínos criados em duas creches com dimensões diferentes, de tipologia abertas, caracterizadas por fluxo de ar natural com controle por meio de janelas e/ou cortinas.

\section{MATERIAL E MÉTODOS}

Este trabalho foi desenvolvido durante o período de inverno de 2005, entre junho e julho, na Suinocultura São Joaquim, município de Urucânia, inserida no polo suinícola do Vale do Piranga, ao norte da Zona da Mata de Minas Gerais, com altitude média de $437 \mathrm{~m}$, definido pelas coordenadas geográficas de $20^{\circ} 21^{\prime} 3^{\prime \prime}$ de latitude sul e $42^{\circ} 44^{\prime} 20^{\prime \prime}$ de longitude oeste.

O clima da região, de acordo com a classificação de Köeppen, é Cwa (quente, temperado, chuvoso, com estação seca no inverno e verão quente). O experimento foi conduzido em condições de inverno, período no qual a concentração de gases dentro das instalações é usualmente maior, em razão de essas permanecerem mais tempo fechadas para proteger os animais do frio.

O experimento foi realizado em duas creches com dimensões e tipologias diferentes, como pode ser observado na Tabela 1.

TABELA 1. Dimensões das creches I e II. Dimensions of I and II farrowing.

\begin{tabular}{cccccccc}
\hline $\begin{array}{l}\text { Tipo de } \\
\text { Creche }\end{array}$ & $\begin{array}{c}\text { Tamanho da } \\
\text { Sala }(\mathrm{m})\end{array}$ & $\begin{array}{c}\text { Pé- } \\
\text {-Direito } \\
(\mathrm{m})\end{array}$ & $\begin{array}{c}\text { Tamanho da Número de } \\
\text { Janela }(\mathrm{m})\end{array}$ & $\begin{array}{c}\text { Tamanho da } \\
\text { Gaiolas }\end{array}$ & $\begin{array}{c}\text { Leitões } \\
\text { Gaiola }(\mathrm{m})\end{array}$ & $\begin{array}{c}\text { Densidade de } \\
\text { Alojados }\end{array}$ & $\begin{array}{c}\text { Leitões por } \\
\mathrm{m}^{2} \text { na Sala }\end{array}$ \\
\hline Creche I & $14,0 \times 4,0$ & 2,70 & $1,50 \times 1,0$ & 10 & $2,40 \times 1,30$ & 110 & 0,50 \\
\hline Creche II & $7,8 \times 5,0$ & 3,00 & $1,0 \times 0,7$ & 6 & $2,80 \times 1,30$ & 84 & 0,46 \\
\hline
\end{tabular}


Ambas as creches eram compostas de gaiolas metálicas suspensas a 0,40 m do chão, cobertura com telhas de fibrocimento, beirais de $0,40 \mathrm{~m}$ de largura; para a circulação do ar, existiam três janelas e uma porta de 2,0 x 1,10 m.

A mesma ração foi oferecida aos animais nas duas granjas, em condições de consumo ad libitum. A água foi disponibilizada à vontade, e o manejo foi similar (dentro de cada fase) em toda a suinocultura, sendo o trato dos animais feito manualmente. A rotina da creche não foi alterada com a execução do experimento. Os animais utilizados foram híbridos adquiridos de empresas de genética idôneas.

As rações foram formuladas de acordo com as recomendações de ROSTAGNO et al. (2005), atendendo às exigências nutricionais de cada fase: pré-iniciais e inicial, conforme Tabela 2.

TABELA 2. Níveis nutricionais das rações utilizadas durante o experimento. Levels of nutritional diets used during the experiment.

\begin{tabular}{lcccc}
\hline Níveis Nutricionais & Unidade & Pré 10-28 dias & Pré 29-42 dias & Inicial 43-60 dias \\
\hline Proteína & $\%$ & 20,168 & 20,540 & 20,922 \\
Gordura & $\%$ & 4,565 & 4,443 & 3,656 \\
Fibra Bruta & $\%$ & 1,810 & 2,260 & 2,870 \\
Cálcio & $\%$ & 0,650 & 0,850 & 0,850 \\
Fósforo disponível NRC & $\%$ & 0,447 & 0,433 & 0,360 \\
ME PIG NRC & $\mathrm{kcal} / \mathrm{k}$ & $3.425,000$ & $3.428,624$ & $3.300,000$ \\
LIS Tot NRC & $\%$ & 1,589 & 1,486 & 1,337 \\
LIS Dig NRC True & $\%$ & 1,461 & 1,353 & 1,200 \\
MET Dig NRC True & $\%$ & 0,494 & 0,440 & 0,378 \\
M+C Dig NRC True & $\%$ & 0,816 & 0,758 & 0,680 \\
TRE Dig NRC True & $\%$ & 0,920 & 0,854 & 0,744 \\
TRI Dig NRC True & $\%$ & 0,248 & 0,236 & 0,254 \\
Sódio (tot) & $\%$ & 0,257 & 0,313 & 0,271 \\
Lactose & $\%$ & 12,206 & 4,613 & \\
\hline
\end{tabular}

Após o desmame, 110 leitões foram encaminhados à creche I e alojados em 10 gaiolas de 11 leitões cada. Já na creche II, foram alojados 84 leitões em 6 gaiolas de 14 leitões cada. Os leitões permaneceram nas salas por 35 dias, saindo das mesmas ao completarem 55 dias de vida. $\mathrm{O}$ manejo foi idêntico nas duas creches quanto às vacinações, trato e limpeza do ambiente, sendo essa última feita com água uma vez ao dia.

Nas duas granjas, foram adotados requisitos básicos relativos ao dimensionamento $\mathrm{m}^{2}$ por animal de um plantel para a produção de suínos em confinamento, de acordo com TEIXEIRA (1997).

Foram feitas medições de concentrações instantâneas de amônia (ppm), monóxido de carbono (ppm) e dióxido de carbono (ppm). Para a coleta de dados de $\mathrm{CO}_{2}$, foi utilizado o sensor da marca Testo®, modelo 535, de "princípio infravermelho", com resolução de $1 \mathrm{ppm}$ e acurácia de \pm 50 ppm, que detecta a concentração instantânea numa faixa de medição de 0 a 10.000 ppm. Para a coleta de dados de CO, foi utilizado sensor da marca Testo®, modelo 315-2, de "princípio eletroquímico", com resolução de 1 ppm e acurácia de \pm 1 ppm, que detecta a concentração instantânea numa faixa de medição de 0 a 100 ppm. Para as concentrações de amônia, foi utilizado sensor da marca Quest ${ }^{\circledR}$, modelo Safecheck 100, de "princípio eletroquímico", com resolução de 1 ppm e acurácia de \pm 1 ppm, que detecta a concentração instantânea numa faixa de medição de 0 a 100 ppm, cuja célula foi calibrada em empresa cadastrada pelo INMETRO. Durante a execução do experimento, os sensores eram ligados fora da instalação, em ambiente neutro, depois eram levados para dentro das creches onde era feita a mensuração normalmente. Esse procedimento era realizado para que 
não ocorresse interferência da mensuração anterior na próxima, conforme orientação técnica do aparelho.

Os gases foram coletados em quatro horários diferentes $(9 ; 12 ; 15$ e $18 \mathrm{~h})$, no período diurno, das salas em avaliação, durante todo o período experimental, na altura dos animais. Convencionalmente, são utilizados os horários $9 \mathrm{~h}$ e $15 \mathrm{~h}$, sendo os outros dois horários estudados (12h e 18h) mensurados para melhor diagnosticar o comportamento dos gases nesse período.

Dados relativos ao conforto térmico ambiente nas creches foram coletados automaticamente, com o uso de dataloggers da marca Testo ${ }^{\circledR}$, modelo $\mathrm{T} 2$, com resolução de $0,1{ }^{\circ} \mathrm{C}$ e acurácia de $\pm 0,5^{\circ} \mathrm{C}$. Esses registraram a temperatura do ar seco, umidade relativa do ar e temperatura de globo negro, de 15 em 15 minutos. Para a obtenção das temperaturas de globo negro, foram utilizados sensores acoplados a dataloggers colocados dentro dos globos negros. Os instrumentos de avaliação de conforto térmico ambiente foram posicionados dentro das instalações a $0,30 \mathrm{~m}$ da altura dos animais avaliados.

Os dados de desempenho relativos ao consumo de ração foram obtidos pesando-se a ração total consumida durante o período experimental, sendo o ganho de peso dos animais determinado por meio da diferença entre o peso de entrada dos animais na creche e o peso de saída do mesmo local.

Os dados foram submetidos à análise de variância, e as médias foram avaliadas, utilizando-se do teste $\mathrm{F}$, adotando-se o nível de $5 \%$ de probabilidade.

\section{RESULTADOS E DISCUSSÃO}

\section{$\mathrm{CO}_{2}$ (dióxido de carbono), $\mathrm{NH}_{3}$ (amônia) e $\mathrm{CO}$ (monóxido de carbono) nas creches}

Observa-se que as concentrações médias de $\mathrm{CO}_{2}$ não diferiram entre si nas duas creches estudadas, mas os níveis de concentração de $\mathrm{CO}_{2}$ obtidos na creche II foram superiores àqueles obtidos na creche I em todos os horários de avaliação. Esse fato pode ser explicado pelo maior número de animais alojados na creche I em relação à creche II, uma vez que a concentração desse gás é associada à respiração e, consequentemente, ao número de animais alojados.

Os valores de $\mathrm{CO}_{2}$ encontrados em ambas as creches, em todos os horários de observação, estiveram abaixo do nível de concentração que possa causar danos à saúde do animal (3.000 ppm), conforme valores citado por NADER et al. (2002), indicando que houve renovação de ar satisfatória do ponto de vista do gás $\mathrm{CO}_{2}$.

Observa-se, também, que houve diferença significativa $(\mathrm{P}<0,05)$ entre as concentrações de amônia, nas duas creches, nos horários de 9; 12 e 15h, sendo os valores encontrados na creche II superiores àqueles obtidos na creche I, nesses períodos de observação. Como ambas as creches permanecem a maior parte do dia com as portas e janelas fechadas (para manutenção do calor dentro do ambiente por causa dos leitões), a creche II fica favorecida pela dispersão dos gases devido a sua maior área, o que leva à menor concentração dos mesmos no ambiente aéreo.

No horário correspondente às $18 \mathrm{~h}$, não houve diferença significativa entre os valores de concentração de amônia, apesar de os valores absolutos de concentração de amônia encontrados na creche II persistirem superiores aos da creche I.

Apesar de ser significativa a diferença de concentração de amônia dos tratamentos na maioria dos horários de observação, verificou-se que os maiores valores da amônia encontrados em ambas as creches não ultrapassaram 7 ppm, valores esses inferiores àqueles que possam afetar a saúde do animal, conforme citado por NIOSH (2005) e CARVALHO (2001), indicando boas condições de ventilação e renovação do ar ambiente.

O gás CO não foi percebido pelo equipamento de medição em nenhuma das creches pesquisadas. 
Os valores médios de $\mathrm{CO}_{2}$ e de $\mathrm{NH}_{3}$, em ppm, obtidos durante todo o período experimental (4 a 8 semanas de vida dos suínos) para as respectivas combinações de creche (creche I e creche II), e horários $(9 ; 12 ; 15$ e 18 h) encontram-se apresentadas na Tabela 3.

TABELA 3. Valores médios de $\mathrm{CO}_{2}$ e $\mathrm{NH}_{3}$, em ppm, para as respectivas combinações de horários $\left(9 ; 12 ; 15\right.$ e $18 \mathrm{~h}$ ) e creches (I e II). Average values of $\mathbf{C O}_{\mathbf{2}}$ and $\mathbf{N H}_{3}$, in $\mathbf{~ p p m}$, for the respective combinations of time (9 am, 12; 3 and 6 pm) and farrowing (I and II).

\begin{tabular}{cccccc}
\hline Gás & Local & $\mathrm{H}=9$ horas & $\mathrm{H}=12$ horas & $\mathrm{H}=15$ horas & $\mathrm{H}=18$ horas \\
\hline \multirow{2}{*}{$\mathrm{CO}_{2}$} & Creche I & $1.204 \mathrm{~A}$ & $997 \mathrm{~A}$ & $1.006 \mathrm{~A}$ & $1.268 \mathrm{~A}$ \\
& Creche II & $1.013 \mathrm{~A}$ & $876 \mathrm{~A}$ & $956 \mathrm{~A}$ & $1.251 \mathrm{~A}$ \\
\multirow{2}{*}{$\mathrm{NH}_{3}$} & Creche I & $3,4 \mathrm{~B}$ & $2,9 \mathrm{~B}$ & $0,6 \mathrm{~B}$ & $0,1 \mathrm{~A}$ \\
& Creche II & $5,3 \mathrm{~A}$ & $6,2 \mathrm{~A}$ & $2,7 \mathrm{~A}$ & $0,4 \mathrm{~A}$ \\
\hline
\end{tabular}

As médias seguidas pela mesma letra na coluna não diferem entre si, a 5\% de probabilidade, pelo teste $\mathrm{F}$.

\section{Temperatura, umidade relativa e ITGU nas creches avaliadas}

Com base na Tabela 4, pode-se observar que, nos horários de 22 até $8 \mathrm{~h}$ da manhã, as temperaturas do ar da creche I são menores que na creche II e estatisticamente diferentes $(\mathrm{P}<0,05)$. Nos outros horários, entre 9 e $21 \mathrm{~h}$, as temperaturas são estatisticamente iguais, ainda assim, na creche I, nos períodos mais quentes (11 às $18 \mathrm{~h}$ ), as temperaturas são menores que na creche II. Isso demonstra que a creche I tem menor amplitude térmica que a creche II, o que pode ser devido ao fato de que as creches têm dimensões diferentes, onde a creche II, devido à menor área para renovação, menor tamanho de janelas e por manter-se fechada para a conservação do calor interno, consegue conservar melhor a temperatura ambiente, atenuando a oscilação da mesma.

Os valores médios de umidade relativa do ar nos horários entre 22 e $10 \mathrm{~h}$ na creche II foram estatisticamente diferentes e inferiores aos obtidos na creche I. Nas demais observações de horários, os valores absolutos de umidade relativa mantiveram-se relativamente menores na creche II, porém não houve diferença estatística entre os mesmos. Similarmente ao que aconteceu à temperatura, a amplitude da umidade relativa do ar foi menor na creche II. Como o experimento foi desenvolvido em período de inverno e não existia nenhuma forma de aquecimento artificial nas salas de creche, essas permaneciam grande parte do dia e durante todas as noites fechadas; sendo assim, a creche II conseguiu amenizar a amplitude dos índices térmicos obtidos em seu interior.

Quanto aos resultados de ITGU encontrados nas creches avaliadas, pode-se observar que os maiores valores desse índice foram obtidos entre 11 e $18 \mathrm{~h}$ nas duas creches, o que pode ser explicado pelo fato de que esse é o período mais quente do dia. Esses valores podem ser considerados dentro do conforto térmico para leitões, conforme descrito por TOLON \& NÄ̈̈S, 2005.

$\mathrm{Na}$ Tabela 4, apresentam-se os valores médios de temperatura, umidade relativa e ITGU nas creches I e II, em função das horas do dia. 
TABELA 4. Valores médios de temperatura do ar, umidade relativa do ar e índice de umidade e temperatura de globo negro (ITGU) para as respectivas combinações de hora (1 a $24 \mathrm{~h}$ ) e creches (I e II). Average values of air temperature, relative humidity and temperature and black-globe-humidity Index (BGHI) for their respective hour combinations (1 to 24 hours) and farrowing (I and II).

\begin{tabular}{ccccccc}
\hline \multirow{2}{*}{ Hora } & \multicolumn{2}{c}{ Temperatura $\left({ }^{\circ} \mathrm{C}\right)$} & \multicolumn{2}{c}{ UR $(\%)$} & \multicolumn{2}{c}{ ITGU } \\
\cline { 2 - 7 } & Creche I & Creche II & Creche I & Creche II & Creche I & Creche II \\
\hline 1 & $22,0 \mathrm{~B}$ & $24,2 \mathrm{~A}$ & $86,5 \mathrm{~A}$ & $77,1 \mathrm{~B}$ & $70,2 \mathrm{~B}$ & $72,0 \mathrm{~A}$ \\
2 & $21,8 \mathrm{~B}$ & $24,2 \mathrm{~A}$ & $86,8 \mathrm{~A}$ & $76,8 \mathrm{~B}$ & $69,8 \mathrm{~B}$ & $71,6 \mathrm{~A}$ \\
3 & $21,6 \mathrm{~B}$ & $24,1 \mathrm{~A}$ & $87,3 \mathrm{~A}$ & $76,7 \mathrm{~B}$ & $69,7 \mathrm{~B}$ & $71,3 \mathrm{~A}$ \\
4 & $21,5 \mathrm{~B}$ & $23,8 \mathrm{~A}$ & $87,4 \mathrm{~A}$ & $77,5 \mathrm{~B}$ & $69,5 \mathrm{~B}$ & $71,1 \mathrm{~A}$ \\
5 & $21,3 \mathrm{~B}$ & $23,5 \mathrm{~A}$ & $87,7 \mathrm{~A}$ & $79,4 \mathrm{~B}$ & $69,2 \mathrm{~B}$ & $70,9 \mathrm{~A}$ \\
6 & $21,1 \mathrm{~B}$ & $23,1 \mathrm{~A}$ & $87,9 \mathrm{~A}$ & $81,2 \mathrm{~B}$ & $69,0 \mathrm{~B}$ & $70,7 \mathrm{~A}$ \\
7 & $21,1 \mathrm{~B}$ & $22,8 \mathrm{~A}$ & $88,3 \mathrm{~A}$ & $82,9 \mathrm{~B}$ & $68,9 \mathrm{~B}$ & $70,7 \mathrm{~A}$ \\
8 & $21,7 \mathrm{~B}$ & $23,0 \mathrm{~A}$ & $89,1 \mathrm{~A}$ & $84,0 \mathrm{~B}$ & $69,4 \mathrm{~B}$ & $71,3 \mathrm{~A}$ \\
9 & $23,1 \mathrm{~A}$ & $23,8 \mathrm{~A}$ & $88,5 \mathrm{~A}$ & $83,1 \mathrm{~B}$ & $71,1 \mathrm{~B}$ & $72,2 \mathrm{~A}$ \\
10 & $24,8 \mathrm{~A}$ & $25,5 \mathrm{~A}$ & $83,2 \mathrm{~A}$ & $78,6 \mathrm{~B}$ & $73,3 \mathrm{~A}$ & $74,0 \mathrm{~A}$ \\
11 & $26,4 \mathrm{~A}$ & $26,7 \mathrm{~A}$ & $74,7 \mathrm{~A}$ & $71,5 \mathrm{~A}$ & $75,0 \mathrm{~A}$ & $75,3 \mathrm{~A}$ \\
12 & $27,9 \mathrm{~A}$ & $27,5 \mathrm{~A}$ & $67,6 \mathrm{~A}$ & $65,4 \mathrm{~A}$ & $76,4 \mathrm{~A}$ & $75,6 \mathrm{~A}$ \\
13 & $29,1 \mathrm{~A}$ & $27,9 \mathrm{~A}$ & $63,3 \mathrm{~A}$ & $63,2 \mathrm{~A}$ & $77,8 \mathrm{~A}$ & $77,1 \mathrm{~A}$ \\
14 & $29,5 \mathrm{~A}$ & $28,6 \mathrm{~A}$ & $61,4 \mathrm{~A}$ & $61,7 \mathrm{~A}$ & $78,3 \mathrm{~A}$ & $77,6 \mathrm{~A}$ \\
15 & $29,5 \mathrm{~A}$ & $28,6 \mathrm{~A}$ & $60,5 \mathrm{~A}$ & $61,4 \mathrm{~A}$ & $78,4 \mathrm{~A}$ & $77,7 \mathrm{~A}$ \\
16 & $29,3 \mathrm{~A}$ & $28,4 \mathrm{~A}$ & $61,6 \mathrm{~A}$ & $64,1 \mathrm{~A}$ & $78,3 \mathrm{~A}$ & $78,0 \mathrm{~A}$ \\
17 & $28,3 \mathrm{~A}$ & $28,1 \mathrm{~A}$ & $70,2 \mathrm{~A}$ & $72,6 \mathrm{~A}$ & $77,4 \mathrm{~B}$ & $78,5 \mathrm{~A}$ \\
18 & $26,8 \mathrm{~A}$ & $26,9 \mathrm{~A}$ & $74,0 \mathrm{~A}$ & $76,9 \mathrm{~A}$ & $75,9 \mathrm{~B}$ & $77,9 \mathrm{~A}$ \\
19 & $25,4 \mathrm{~A}$ & $25,8 \mathrm{~A}$ & $78,5 \mathrm{~A}$ & $78,6 \mathrm{~A}$ & $74,3 \mathrm{~B}$ & $76,4 \mathrm{~A}$ \\
20 & $24,5 \mathrm{~A}$ & $25,2 \mathrm{~A}$ & $81,0 \mathrm{~A}$ & $79,6 \mathrm{~A}$ & $73,2 \mathrm{~B}$ & $75,5 \mathrm{~A}$ \\
21 & $23,8 \mathrm{~A}$ & $24,9 \mathrm{~A}$ & $83,0 \mathrm{~A}$ & $80,1 \mathrm{~A}$ & $72,4 \mathrm{~B}$ & $74,6 \mathrm{~A}$ \\
22 & $23,4 \mathrm{~B}$ & $24,9 \mathrm{~A}$ & $84,3 \mathrm{~A}$ & $79,5 \mathrm{~B}$ & $71,8 \mathrm{~B}$ & $74,0 \mathrm{~A}$ \\
23 & $22,9 \mathrm{~B}$ & $24,9 \mathrm{~A}$ & $85,4 \mathrm{~A}$ & $78,0 \mathrm{~B}$ & $71,3 \mathrm{~B}$ & $73,4 \mathrm{~A}$ \\
24 & $22,5 \mathrm{~B}$ & $24,7 \mathrm{~A}$ & $85,7 \mathrm{~A}$ & $76,8 \mathrm{~B}$ & $70,8 \mathrm{~B}$ & $72,7 \mathrm{~A}$ \\
\hline
\end{tabular}

Médias seguidas de mesma letra na linha não diferem entre si, a $5 \%$ de probabilidade, pelo teste $\mathrm{F}$.

\section{Dados de desempenho animal}

Como pode ser observado na Tabela 5, na qual estão descritos os dados relativos ao desempenho dos leitões, pode-se observar que os animais que estavam presentes na creche II obtiveram maior ganho diário de peso e menor consumo diário de ração do que aqueles alojados na creche I. Essa pior conversão alimentar da creche I pode ter sido influenciada pela maior amplitude térmica ocorrida dentro dessa da sala, uma vez que a média da temperatura mínima ocorrida na creche I foi de $21,1^{\circ} \mathrm{C}$ e na creche II foi de $22,8^{\circ} \mathrm{C}$, enquanto a média da temperatura máxima da creche I foi de $29,5^{\circ} \mathrm{C}$ e da creche II foi $28,6^{\circ} \mathrm{C}$. Nessas condições, os animais da creche I podem ter gastado mais energia com a manutenção da homeotérmica (BAÊTA \& SOUZA, 1997), e a maior amplitude térmica da temperatura da sala afetou negativamente o desempenho dos leitões, conforme constatado por QUINIOUN et al. (2000). 
TABELA 5. Dados descritivos do desempenho dos leitões dentro de cada creche (I e II). Descriptive data of the performance of piglets in each farrowing (I and II).

\begin{tabular}{lcccc}
\hline & $\begin{array}{c}\text { Peso ao Sair da } \\
\text { Creche }(\mathrm{kg})\end{array}$ & $\begin{array}{c}\text { Ganho Diário de } \\
\text { Peso }(\mathrm{kg})\end{array}$ & $\begin{array}{c}\text { Consumo Diário de } \\
\text { Ração }(\mathrm{kg})\end{array}$ & $\begin{array}{c}\text { Consumo Total de Ração } \\
\text { por Leitão }(\mathrm{kg})\end{array}$ \\
\hline Creche I & 18,470 & 0,360 & 0,600 & 21,000 \\
Creche II & 18,690 & 0,390 & 0,522 & 19,000 \\
\hline
\end{tabular}

\section{CONCLUSÕES}

A concentração dos gases $\mathrm{CO}_{2}$ e $\mathrm{NH}_{3}$, mensurados nas creches, não atingiu níveis que possam causar danos à saúde dos animais.

Não houve concentração mensurável do gás monóxido de carbono em nenhuma das creches avaliadas.

De forma geral, o ambiente térmico nas creches, no período estudado, estiveram em condições consideradas confortáveis para os animais nessa fase, sendo que a creche com menor dimensão (creche I) apresentou menor amplitude térmica e melhor desempenho dos leitões.

\section{AGRADECIMENTOS}

À Coordenação de Aperfeiçoamento de Pessoal de Nível Superior (CAPES) e ao Conselho Nacional de Desenvolvimento Científico e Tecnológico $(\mathrm{CNPq})$, pelo apoio financeiro à pesquisa.

\section{REFERÊNCIAS}

BAÊTA, F.C.; SOUZA, C.F. Ambiência em edificações rurais: conforto animal. Viçosa: Editora UFV, 1997. 246 p.

BUFFINGTON, D.E.; COLLAZO-AROCHO, A.; CANTON, G.H.; PITT, D.; THATCHER, W.W.; COLLIER, R.J. Black globe humidity index (BGHI) as comfort equation for dairy cows. Transactions of the ASAE, St. Joseph, v.24, n.3, p.711-714, 1981.

CARVALHO, L.F.O.S. Doenças respiratórias dos suínos. In: SIMPÓSIO SOBRE MANEJO E NUTRIÇÃO DE AVES E SUÍNOS E TECNOLOGIA DA PRODUÇÃO DE RAÇÕES, 2001, Campinas. Anais... Campinas: Colégio Brasileiro de Nutrição Animal, 2001. p.237-262.

JENSEN, A.O. Changing the environment in swine buildings using sulfuric acid. American Society of Agricultural Engineers, St. Joseph, v.45, n.1, p.223-227, 2002.

LOTT, B. El amoníaco puede causar perdidas importantes. Indústria Avícola, Mount Morris, v.50, n.10, p.8-10, 2003.

NADER, A.S.; BARACHO, M.S.; NÄÄS, I.A.; SAMPAIO, C.A.P. Avaliação da qualidade do ar em creche de suínos. In: SEMINÁRIO POLUENTES AÉREOS E RUÍDOS EM INSTALAÇÕES PARA PRODUÇÃO DE ANIMAIS, 2002, Campinas. Anais... Campinas: UNICAMP, 2002. p.4956.

NIOSH. NATIONAL INSTITUTE FOR OCCUPATIONAL SAFETY AND HEALTH. Disponível em: <http://www.cdc.gov/niosh/pel88/7664-41.html>. Acesso em: 2 abril 2005.

QUINIOUN, N.; MASSABIE, P.; GRANIER, R. Diurnally variation of ambient temperature around 24 ou $28^{\circ}$ : Influence on performance and feeding behavior of growing pigs. In:

INTERNATIONAL CONFERENCE, 1., 2006, Iowa. Proceedings... p.332-339.

ROSTAGNO, H.S.; ALBINO, L.F.T.; DONZELE, J.L.; GOMES, P.C.; OLIVEIRA, R.F.; LOPES, D.C.; FERREIRA, A.S.; BARRETO, S.L.T. Tabelas brasileiras para aves e suínos: composição de alimentos e exigências nutricionais. 2.ed. Viçosa - MG: Departamento de Zootecnia, UFV, 2005. $186 \mathrm{p}$. 
SAMPAIO, C.A.P.; NÄÄS, I.A.; NADER, A. Gases e ruídos em edificações para suínos aplicação das normas NR 15, CIGR e ACGIH. Engenharia Agrícola, Jaboticabal, v.25, n.1, p.1018, 2005.

SAMPAIO, C.A.P.; CRISTIANI, J.; DUBIELA, J.A.; BOFF, C.E.; OLIVEIRA, M.A. Avaliação do ambiente térmico em instalação para crescimento e terminação de suínos utilizando os índices de conforto térmico nas condições tropicais. Ciência Rural, Santa Maria, v.34, n.3, p785-790, 2004.

SARTOR, V.; BAÊTA, F.C.; TINÔCO, I. F.F.; LUZ, M. L. Perfomance of an evaporative cooling system of a finishing phase swine barn. Scientia Agricola, Piracicaba, v.60, n.1, p.13-17, 2003.

SILVA, I.J.O. Qualidade do ambiente e instalações na produção industrial de suínos. In: SEMINÁRIO INTERNACIONAL DE SUINOCULTURA, 4., 1999, São Paulo. Anais... Concórdia: EMBRAPA-CNPSA, 1999. p.108-325.

SCHMIDT, D.R.; JACOBSON, L.D.; JANNI, K.A. Continuous monitoring of ammonia, hydrogen sulfide and dust emissions from swine, dairy and poultry barns. St. Joseph: ASAE, 2002. 14 p.

SOUSA, P. Conforto térmico e bem-estar na suinocultura. I. Lavras: UFLA, 2004. 69 p.

TEIXEIRA, V.H. Construções e ambiência. Lavras: UFLA/FAEPE, 1997.181 p.

TINÔCO, I.F.F. Industrial aviculture: new concepts of materials, conceptions and constructive techniques available for brazilian poultry houses. Revista Brasileira de Ciência Avícola, Campinas, v.3, n.1, p.1-26, 2001.

TINÔCO, I.F.F.; FIGUEIREDO, J.L.A.; SANTOS, R.C.; PAULA, M.O.; VIGODERIS, R.B.; PUGLIESI, N. Avaliação de materiais alternativos utilizados na confecção de placas porosas para sistemas de resfriamento adiabático evaporativo. Revista Brasileira de Engenharia Agrícola e Ambiental, Campina Grande, v.6, n.1, p.147-150, 2002.

TOLON, Y.B.; NÄÄS, I.A. Avaliação de tipos de ventilação em maternidade de suínos. Engenharia Agrícola, Jaboticabal, v.25, n.3, p.565-574, 2005.

TURCO, S.H.N.; BAÊTA, F.C.; CARDOSO, R.M.; CECON, P.R.; SOUZA, C.F. Utilização da ventilação forçada e resfriamento adiabático localizados em maternidades de suínos. In: CONGRESSO BRASILEIRO DE ENGENHARIA AGRÍCOLA, 24., 1995, Viçosa. Anais.... Viçosa: SBEA/UFV, 1995. v.1, p.1-12. 